\title{
Risk factors and spatial distribution of extended spectrum $\beta$-lactamase-producing- Escherichia coli at retail poultry meat markets in Malaysia: a cross-sectional study
}

\author{
A. B. Aliyu ${ }^{1}$, A. A. Saleha ${ }^{1,3^{*}}$, A. Jalila ${ }^{2}$ and Z. Zunita ${ }^{1}$
}

\begin{abstract}
Background: The significant role of retail poultry meat as an important exposure pathway for the acquisition and transmission of extended spectrum $\beta$-lactamase-producing Escherichia coli (ESBL-EC) into the human population warrants understanding concerning those operational practices associated with dissemination of ESBL-EC in poultry meat retailing. Hence, the objective of this study was to determine the prevalence, spatial distribution and potential risk factors associated with the dissemination of ESBL-EC in poultry meat retail at wet-markets in Selangor, Malaysia.

Methods: Poultry meat (breast, wing, thigh, and keel) as well as the contact surfaces of weighing scales and cutting boards were sampled to detect ESBL-EC by using culture and disk combination methods and polymerase chain reaction assays. Besides, questionnaire was used to obtain data and information pertaining to those operational practices that may possibly explain the occurrence of ESBL-EC. The data were analysed using logistic regression analysis at $95 \% \mathrm{Cl}$.

Results: The overall prevalence of ESBL-EC was $48.8 \%$ (95\% Cl, 42 - $55 \%$ ). Among the risk factors that were explored, type of countertop, sanitation of the stall environment, source of cleaning water, and type of cutting board were found to be significantly associated with the presence of ESBL-EC.

Conclusions: Thus, in order to prevent or reduce the presence of ESBL-EC and other contaminants at the retailoutlet, there is a need to design a process control system based on the current prevailing practices in order to reduce cross contamination, as well as to improve food safety and consumer health.
\end{abstract}

Keywords: ESBL- E. coli, Zoonosis, Foodborne infection, Antimicrobial resistance, Poultry meat, Wet-market, Risk factor, Malaysia

\section{Background}

Poultry meat constitutes a greater percentage of human protein sources; however, it may also serve as an important medium for the transfer of multidrug-resistant bacteria, such as extended spectrum $\beta$-lactamase-producing Escherichia coli (ESBL-EC), from food-producing animals to the consumers. ESBL-EC is an emerging

\footnotetext{
* Correspondence: saleha@upm.edu.my

'Department of Veterinary Pathology and Microbiology, Faculty of Veterinary Medicine, University Putra Malaysia, 43400 Serdang, Selangor, Malaysia ${ }^{3}$ Department of Pathology and Microbiology, Faculty of Veterinary Medicine, Veterinary Public health laboratory, Universiti Putra Malaysia, 43400 Serdang, Selangor, Malaysia

Full list of author information is available at the end of the article
}

zoonotic and a multidrug-resistant bacterium, which has currently posed a major challenge in antimicrobial treatments [1]. Antimicrobial resistance and food safety in recent years, have received global attention over their huge impact on population health and global economy [2].

Besides, molecular epidemiological studies have shown that large proportions of resistant E. coli causing blood stream infections within human population are of food animal origin [3, 4]. According to WHO global report on antimicrobial resistance [2], ESBL-EC is among the most frequent causes of blood stream infection, community and hospital acquired urinary tract infection, also 
with the associated increase in mortality rate and cost of hospitalization, prolonged hospital stay, as well as the world most leading cause of foodborne infection. Foodborne infection with ESBL-EC, moreover, has been associated with limited therapeutic options, prolong duration of infection, high rate of treatment failure with increased morbidity, and mortality rate $[5,6]$.

Furthermore, several studies have consistently revealed the role of retail poultry meat in the transmission of multidrug resistant bacteria among human population and their environment, resulting in increased challenge to food safety and environmental health [7]. Other than that horizontal transfer of ESBL-EC has been believed to be the major pathway that fosters its global dissemination [8] through improper handling of poultry during slaughtering, dressing and other meat processing operations as well as at retailing.

Thus, ESBL-EC has been reported as a threatening issue in the Malaysian healthcare setting [9, 10], in addition to several research reports demonstrating the potential role of retail poultry meat as a major reservoir for human exposure to ESBL-EC [7, 11, 12]. However, little or no study has been conducted to study its prevalence and the risk factors that may foster its dissemination at retail poultry meat-markets in Malaysia. Hence, the objective of this study was to determine the prevalence and risk factors associated with ESBL-EC at retail poultry meat wet-markets in Selangor, Malaysia.

\section{Methods}

\section{Study area}

Selangor is one of the 13 states of Malaysia; with a total area of $8,104 \mathrm{~km}^{2}$, the Malaysia's most populous state, also known as the industrial hub of Malaysia, with the largest economy in terms of gross domestic product (GDP), providing almost $23 \%$ of Malaysian GDP; it is located at centre of Peninsular Malaysia [13-15]. Almost $90 \%$ of Malaysian poultry production is in peninsular Malaysia (while the remaining is in East Malaysia), which was reported to be among the world highest per capita consumption of poultry meat at $40 \mathrm{~kg}$ per year [16]. Poultry meat is the most stable protein source across all ethnic groups of the Malaysian population [16]. According to the USDA recent International Egg and Poultry review [17], Malaysia is self-sufficient in poultry meat production, which was almost entirely of broiler meat, with production forecast at 1.44 million tons; about $40 \%$ are marketed to the consumers through wet-markets [17].

\section{Collection of sample}

A total of 240 samples comprising 160 broiler chicken meat samples (breast, wing, thigh, and keel) and 80 swab samples from contact surfaces (weighing scales and cutting boards/instrument) were examined to detect the presence of ESBL-EC. The estimated sample size was calculated using G*Power 3.1.9.2, using A priori Ftests ANOVA: Fixed effects, omnibus, and one-way; given $\alpha=0.05$, Power $=0.80$, Effect size $=0.25$, Number of groups $=8$. Informed consents were obtained from each participant prior to sample collection and questionnaire administration. The participants were informed about the purpose of the research, likewise they were assured of protecting their identities and received information would be highly confidential, as it was only used for research purpose.

A total number of 40 individual stalls were selected at random within eight districts in Selangor (Table 2). Three wet-markets were selected in every district, out of which five different stalls were recruited to represent a district area. At each stall, six representative samples were obtained, which consisted of four broiler chicken meats (breast, keel, wing and thigh) and two swabs (weighing scale and cutting board/instrument). The meat samples were bagged separately in a sterile plastic bag. The surfaces of the cutting board/instrument and weighing scale covering an area of $25 \mathrm{~cm}^{2}$ were swabbed using pre-moistened sterile cotton swab, [18], and each swab was placed in sterile transport media containing $9 \mathrm{ml}$ of peptone water (Oxoid). All samples were transported to the laboratory in ice cool box and processed within five hours of collection.

\section{Sample preparation}

Each meat sample was processed by taking $25 \mathrm{~g}$ of the meat sample, vigorously shaken in a sterile plastic bag containing $225 \mathrm{ml}$ of peptone water and homogenized in a stomacher for $1 \mathrm{~min}$ [19]. Five $\mathrm{ml}$ of each homogenized sample was subsequently placed in $45 \mathrm{ml}$ of peptone water and vortexed gently to form a mixture of processed meat sample. Each of the bottles containing the swab was vortexed gently; then, $1 \mathrm{ml}$ was taken and diluted in $9 \mathrm{ml}$ of peptone water and was further vortexed gently.

\section{E. coli isolation and identification}

A few loopfulls of each processed sample was directly inoculated on Chromocult Coliform agar (Merck, UK) and incubated at $37{ }^{\circ} \mathrm{C}$ for $24 \mathrm{~h}$. The agar served as differential and selective media, it distinguished E. coli from other coliform colonies and inhibited grampositive bacteria growth, which was further confirmed by using Kovac's reagent (the blue-violet E. coli colony becomes red) as indicated by the manufacturer.

\section{Screening for extended spectrum $\beta$-lactamases production}

The non-duplicate representative of $E$. coli isolates were subcultured on CHROMagar ESBL (CHROMagar, Paris, 
France) to screen for the presence of ESBLs [20]. The plates were incubated aerobically overnight at $37{ }^{\circ} \mathrm{C}$. The presumptively identified ESBL-EC colonies were selected (dark pink to reddish colonies) and further subjected to phenotypic confirmation.

\section{Phenotypic confirmation of extended spectrum $\beta$ - lactamases production}

The phenotypic confirmation was conducted by using the Combination Disk Method, as described by CLSI [21]. The bacterial suspension (turbidity of $0.5 \mathrm{McF}$ aland standard) was spread on Mueller-Hinton agar (oxoid) impregnated with cefotaxime (CTX-30 $\mu \mathrm{g})$, ceftazidime (CAZ-30 $\mu \mathrm{g})$, cefotaxime/clavulanic acid (CTX/CV), and ceftazidime/clavulanic acid (CAZ/CV) disks, and incubated at $37{ }^{\circ} \mathrm{C}$ for 16 to $18 \mathrm{~h}$. The interpretation was based on the zones of inhibition produced by cefotaxime (CTX-30 $\mu \mathrm{g})$ and ceftazidime (CAZ-30 $\mu \mathrm{g})$ disks against cefotaxime/clavulanic acid (CTX/CV), and ceftazidime/ clavulanic acid (CAZ/CV) respectively [21]. A difference of $\geq 5 \mathrm{~mm}$ between the zones of CTX and CTX/CV or $\mathrm{CAZ}$ and $\mathrm{CAZ/CV}$ was considered as phenotypically confirmed ESBLs. Klebsiella pneumoniae ATCC 700603 and Escherichia coli ATCC 25922 were used as quality control strains [21].

\section{DNA extraction and PCR amplification}

The DNA of phenotypically confirmed ESBL-EC was isolated by using the boiling method, on 2-3 colonies grown on nutrient agar. The colonies were suspended in $100 \mu \mathrm{l}$ of sterile water, and the suspensions were boiled for $15 \mathrm{~min}$, cooled to $4{ }^{\circ} \mathrm{C}$, and then, subsequently centrifuged for $30 \mathrm{~s}$ at $12000 \times \mathrm{g}$. The supernatant served as a source of DNA template for the PCR, while the specific oligonucleotide primers for $b l a_{\mathrm{TEM}}, b l a_{\mathrm{SHV}}$, $b l a_{\mathrm{CTX}-\mathrm{M}}, b l a_{\mathrm{OXA}}$, and $E$. coli were used for amplifications of these bla-genes and E. coli. Furthermore, MyTaq Protocol (BIOLINE) was used as standard for the PCR reactions and amplification. The sizes of bla $a_{\mathrm{CTX}-\mathrm{M}}$, bla${ }_{\mathrm{TEM}}, b l a_{\mathrm{SHV}}, b l a_{\mathrm{OXA}}$, and $E$. coli amplicons are shown in Table 1, using K. pneumoniae ATCC 700603 and EC1003-1 as positive controls. The amplified products were separated by gel electrophoresis on $1.5 \%$ agarose gels stained with ethidium bromide.

\section{Questionnaire design and definition of terms}

A questionnaire was developed as an instrument to gather information and data for the risk factors analysis. The items were derived from literature search, interviews, and focus group discussions with local veterinarians and representative of butchers. The questionnaire was further evaluated by the research team for face validation. In order to evaluate the adequacy of the instrument content, the questionnaire was further assessed by five experts in the field for content validity. On top of that, the instrument was refined and pilot tested. Unclear items were finally dropped, while items with overlapping meaning were merged together as single items.

\section{Sanitation of the stall environment}

Stall sanitation is classified into three hygiene categories, namely good, fair, and poor. A stall with clean floor, clean countertop, and absence of flies is considered as good; while those with either clean floor/clean counter top, in the absence of flies is considered as fair hygiene; and those with only one of the three characteristics is considered as poor hygiene.

\section{Type of countertop}

Refers to the type of material used as benchtop/working-surface, as there are four types of countertop, namely wooden, tile, plastic-sheet, and stainless-steel.

\section{Source of cleaning water}

Butchers mainly obtain water either directly from running-tap or from a water container, which they use for

Table 1 PCR primers used for the detection $\beta$-lactamase encoding genes

\begin{tabular}{|c|c|c|c|c|}
\hline Target gene & Primer & Sequence $\left(5^{\prime}-3^{\prime}\right)$ & Size of product (bp) & GenBank accession no \\
\hline \multirow[t]{2}{*}{ bla } & Forward & CAATCACGACGGCGGAATCT & 168 & AB731686 \\
\hline & Reverse & GTGGGTCATGTCGGTACCAT & & \\
\hline \multirow[t]{2}{*}{ bla $a_{\text {CTX-M }}$} & Forward & AAGCACGTCAATGGGACGAT & 402 & JN411912 \\
\hline & Reverse & GTTGGTGGTGCCATAGCCA & & \\
\hline \multirow[t]{2}{*}{$b l a_{\mathrm{TEM}}$} & Forward & TCCTTGAGAGTTTTCGCCCC & 643 & EU352903 \\
\hline & Reverse & TGACTCCCCGTCGTGTAGAT & & \\
\hline \multirow[t]{2}{*}{$b l a_{\mathrm{OXA}}$} & Forward & TTGCACTTGATAGTGGTGTGA & 250 & JN003412 \\
\hline & Reverse & AGTGAGTTGTCAAGCCAAAAAGT & & \\
\hline \multirow[t]{2}{*}{ E. coli } & Forward & TGACGTTACCCGCAGAAGAA & 832 & X80724 \\
\hline & Reverse & CTCCAATCCGGACTACGACG & & \\
\hline
\end{tabular}


washing hands, as well as sanitising utensils, equipment, and other contact surfaces throughout the meat selling/ processing period.

\section{Type of cutting board/instrument}

Refers to the type of material used by butchers as chopping-block. Two types of cutting boards were identified, namely rubberwood (wooden), polyethylene cutting board (plastic); and the cutting instrument was an electric meat cutter made of stainless steel.

\section{Statistical analysis}

Data were analysed by using SPSS version 20. chisquare test was used to compare the prevalence; whereas the relationship between potential risk factors and detection of ESBL-EC was explored by using univariate logistic regression at $95 \%$ confidence interval (95 \% CI). However, only factors that were found to be significantly associated with detection of ESBL-EC had been included in the multivariate logistic regression model for estimation of their odds ratio at $95 \% \mathrm{CI}$.

\section{Results}

\section{Spatial distribution of ESBL-EC}

A total of 240 samples were collected in wet-markets within eight districts of Selangor from July -2012 to February 2013. The overall prevalence of ESBL-EC was $48.8 \%(95 \% \mathrm{CI}, 42-55 \%)$, although the difference in prevalence was not statistically significant between the districts $(\chi 2=6.921, d f=7, \mathrm{p}=.437)$ with chi-square test at $95 \%$ confidence interval (95\% CI). Stalls in the district of Hulu Selangor were shown to have the highest prevalence at $66.7 \%$. while moderate prevalence was observed in Hulu Langat at $56.7 \%$ and Kuala Selangor at $50 \%$. Nevertheless, the lowest prevalence was found in Klang at $46.7 \%$, Sepang at $46.7 \%$, Petaling at $43.3 \%$, Gombak at $40 \%$, and Kuala Langat at 40 \% (Fig. 1; Table 2).

However, when the occurrence of ESBL-EC in meat was compared to that of the contact surfaces, the meat samples displayed higher occurrence rate of $53.8 \%$ compared to contact surfaces at $38.8 \%$ (Fig. 2; Table 3).

Furthermore, more than $50 \%$ of the meats sampled were contaminated with ESBL-EC; the highest occurrence was in breast, wing, and thigh with proportions of 65,52 , and $50 \%$ respectively. Keel and weighing scale had moderate rates, while cutting board/instrument had rather lower rates at 47.5, 40, and $37.5 \%$ respectively (Table 4).

\section{Risk factors associated with ESBL-EC contamination} Univariable logistic regression model indicated four factors that had the likelihood of causing ESBL-EC contamination, at $p$-value less than 0.05 , which included stall sanitation, type of counter top, source of cleaning water, and type of cutting board/instrument (Table 5).

However, based on the multivariable logistic regression model, only two factors significantly predicted ESBL-EC contamination, which were stall sanitation, and type of countertop (Table 5).

\section{Discussion}

The distribution of ESBLs has been found to be varied worldwide, with Asia having the highest prevalence [22]. Base on study for Monitoring Antimicrobial Resistance Trends (SMART) in 2007, Asia-Pacific Region reported highest prevalence of ESBL-EC in India, China, and Thailand at 79.0, 55.0, and $50.8 \%$ respectively. Meanwhile, moderate distribution of ESBLs was discovered in Vietnam, Singapore, and South Korea, at 34.4, 33.3 and $22.7 \%$ respectively, and the least from Hong Kong, Philippines, Taiwan, Australia, and New Zealand at 17.8, 17.0, 12.7, 7.7, and 3.2\% respectively [23]. In Malaysia, Hashim et al. [10] reported 73.7 \% of ESBL- K. pneumonia and $8.8 \%$ of ESBL-EC among drug resistant bacteria isolated from the largest Malaysian tertiary referral hospital [10].

Environment, workers, equipment, and contaminated chicken were reported to be the major sources of meat contamination at retail outlets mainly due to improper hygiene practices and poor environmental sanitation. These factors favour the survival, proliferation, dissemination, and cross-contamination of retail meat and its environment with microbial agents [24-26]. At retail stalls, raw and packaged chicken drips continue to seep around stall environment, hence cross-contaminating meat, countertop, other contact surfaces, as well as floor [26, 27], more so, it might increase chances of occupational exposure especially via accidental cuts from contaminated utensils. Studies also have shown that thorough cleaning and regular disinfecting meat processing environment serves as important factor in reducing the risk of cross-contamination within meat processing environment $[28,29]$.

The present study had investigated the role of environmental sanitation in the likelihood of the occurrence of ESBL-EC on the meat. At univariate logistic model, it was found that stalls with poor sanitary environment were 6 times more at risk of ESBL-EC contamination in comparison to those with good hygiene (OR 6.044, $95 \%$ $\mathrm{CI}=3.007-12.148$ ), while those with fair hygiene had twice the risk in contrast to those with good hygiene environment (OR 2.346, $95 \% \mathrm{CI}=1.154-4.770$ ). Apart from the above mentioned cross-contamination factors that may favour the observed occurrence, most of these chicken meats were placed on countertop 


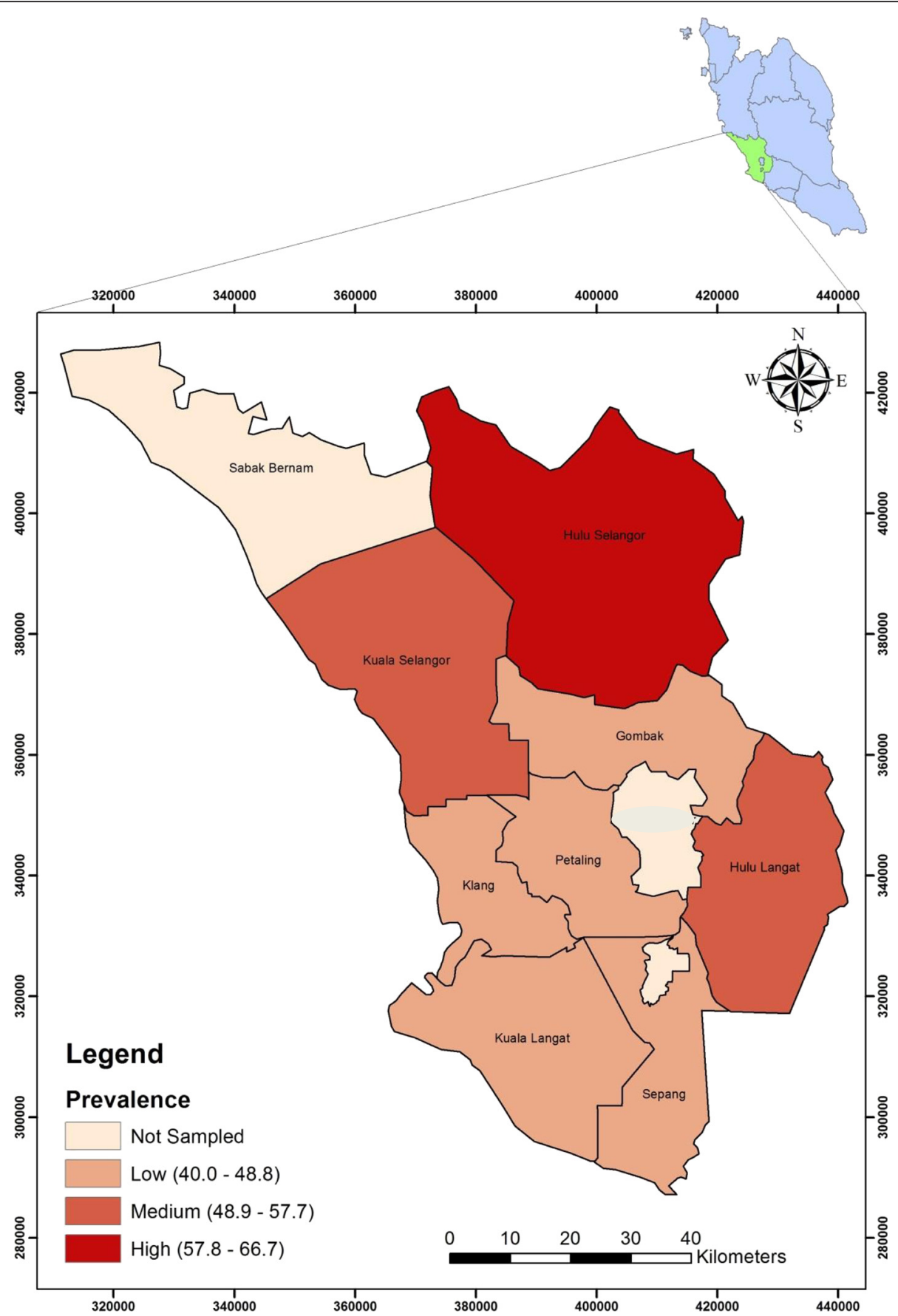

Fig. 1 Choropleth map of spatial distribution of ESBL-EC in Selangor, Malaysia

without being chilled, such as using ice. Thus, the warm condition favours the survival and the multiplication of ESBL-EC, which can remain infectious for a long period even under adverse environmental condition $[27,30]$.

In addition, working surface or countertop has also been shown to play an important role in the dissemination of microorganisms at processing and retailing outlets. The question is what type of countertop surface material poses greater risk to food in relation to cross-contamination? and this depends on the availability of both intrinsic and extrinsic factors that allow bacterial survival, growth, and proliferation on the surface material [31, 32]. At univariate logistic model, the 
Table 2 Prevalence of ESBL-EC at retail poultry meat wetmarkets

\begin{tabular}{llll}
\hline District area & No. of samples & $\begin{array}{l}\text { No. of positive } \\
\text { samples }\end{array}$ & Prevalence \% \\
\hline Hulu Selangor & 30 & 20 & 66.7 \\
Hulu langat & 30 & 17 & 56.7 \\
Kuala Selangor & 30 & 15 & 50.0 \\
Klang & 30 & 14 & 46.7 \\
Sepang & 30 & 14 & 46.7 \\
Petaling & 30 & 13 & 43.3 \\
Gombak & 30 & 12 & 40.0 \\
Kuala Langat & 30 & 12 & 40.0 \\
Total ESBL & 240 & 117 & 48.8 \\
\hline
\end{tabular}

current study found that vendors who used working surfaces or countertops made of wooden material had 8.1 times the risk of contamination with ESBL-EC compared to stainless steel (OR 8.125, $95 \% \mathrm{CI}=2.509-26.311$ ), while tiles countertops had 4.2 times the risk of ESBLEC contamination than stainless steel (OR 4.212, $95 \%$ $\mathrm{CI}=2.134-8.314)$. Nonetheless, the plastic-sheet covered countertop showed to have 3.7 times more risk of contamination than stainless-steel (OR 3.693, $95 \% \mathrm{CI}=1.660-8.216$ ).

In fact, both cutting board and working surface/countertop were reported to share similar factors in terms of cross contamination liability; these factors included board materials, scoring (degree of roughness) on the cutting/contact surfaces and its level of contamination, type of pathogen, part of the chicken and meat temperature during retailing, meat $\mathrm{pH}$ level, and water activity [31, 33-35]. The present study also found that the cutting-board material played significant role in the occurrence of ESBL-EC when using stainless steel cutting-instrument as reference model for comparison. At univariate logistic model, the wooden cutting board was found to have the highest risk of ESBL-EC contamination, at 5.5 times the risk compared to stainless steel (OR 5.50, $95 \% \mathrm{CI}=2.049-14.763$ ), while plastic cutting board had twice the risk of contamination than the stainless steel cutting-instrument (OR 2.419, $95 \% \mathrm{CI}=1.015-5.763)$.

Additionally, one of the unhygienic practices that was revealed worth reporting is the source of water for washing hands and cleaning utensil during retailing. Majority

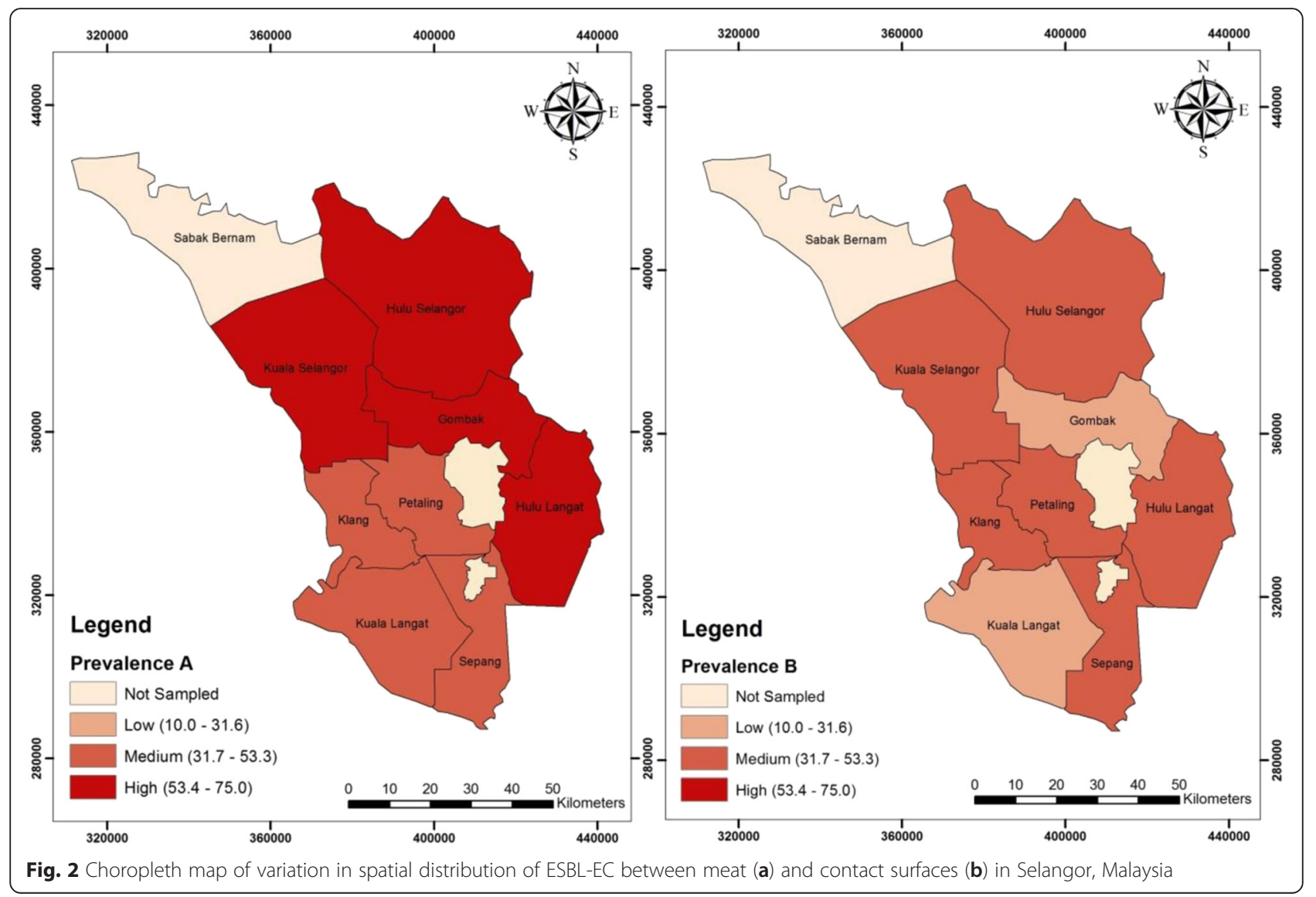


Table 3 Variation in the prevalence of ESBL- EC between meat and its contact surfaces

\begin{tabular}{|c|c|c|c|c|}
\hline \multirow[t]{2}{*}{ District area } & \multicolumn{2}{|c|}{$\begin{array}{l}\text { ESBL- EC in poultry } \\
\text { meat }\end{array}$} & \multicolumn{2}{|c|}{$\begin{array}{l}\text { ESBL- EC in contact } \\
\text { surfaces }\end{array}$} \\
\hline & $\begin{array}{l}\text { No. of } \\
\text { samples }\end{array}$ & Prevalence \% & $\begin{array}{l}\text { No. of } \\
\text { samples }\end{array}$ & Prevalence $\%$ \\
\hline Hulu Selangor & 20 & 75.0 & 10 & 50.0 \\
\hline Hulu Langat & 20 & 65.0 & 10 & 40.0 \\
\hline Gombak & 20 & 55.0 & 10 & 10.0 \\
\hline Kuala Selangor & 20 & 55.0 & 10 & 40.0 \\
\hline Klang & 20 & 50.0 & 10 & 40.0 \\
\hline Kuala Langat & 20 & 45.0 & 10 & 30.0 \\
\hline Sepang & 20 & 45.0 & 10 & 50.0 \\
\hline Petaling & 20 & 40.0 & 10 & 50.0 \\
\hline Total ESBL & 160 & 53.8 & 80 & 38.8 \\
\hline
\end{tabular}

of the meat vendors are using the same water placed in a container to wash their hands and utensils throughout the retailing period, thus the contaminated water continued to contaminate subsequent meat, contact surfaces and processing environment. At univariate logistic model, the present study found that meat vendors who used the same contaminated water for cleaning purpose had thrice the risk of causing cross-contamination compared to those who used direct water from the tap (OR 3.171, $95 \%$ CI = $1.212-8.297$ ).

Apart from temporal ambiguity associated with crosssectional study design, additional limitation of the current study is the lack of data from human sample. This may provide additional information to the observed phenomenon, although attempt has been made to collect rectal swabs from the butchers, but they were reluctant to volunteer.

\section{Conclusion}

Identifying risk factors associated with various components of poultry meat retailing can provide a scientific basis for designing effective risk communication and
Table 5 Univariable and multivariable factors associated with ESBL-EC at retail poultry meat wet-markets

\begin{tabular}{|c|c|c|c|c|}
\hline \multirow[t]{2}{*}{ Variables } & \multicolumn{2}{|c|}{ Univariable analysis } & \multicolumn{2}{|c|}{ Multivariable analysis } \\
\hline & $\overline{\mathrm{OR}^{\mathrm{a}}}$ & $95 \% \mathrm{Cl}^{\mathrm{b}}$ & $\overline{\mathrm{OR}^{a}}$ & $95 \% \mathrm{Cl}^{\mathrm{b}}$ \\
\hline \multicolumn{5}{|l|}{ Stall sanitation } \\
\hline Poor & 6.044 & $3.007-12.148^{* *}$ & 3.122 & $1.319-7.391^{*}$ \\
\hline Fair & 2.346 & $1.154-4.770^{*}$ & & \\
\hline Good & 1.00 & Ref & & \\
\hline \multicolumn{5}{|l|}{ Type of counter top } \\
\hline Wooden counter & 8.125 & $2.509-26.311^{* *}$ & 3.789 & $1.045-13.741^{*}$ \\
\hline Tiles counter & 4.212 & $2.134-8.314^{* *}$ & & \\
\hline Plastic sheet & 3.693 & $1.660-8.216^{* *}$ & & \\
\hline $\begin{array}{l}\text { Stainless steel } \\
\text { counter }\end{array}$ & 1.00 & Ref & & \\
\hline \multicolumn{5}{|l|}{$\begin{array}{l}\text { Source of cleaning } \\
\text { water }\end{array}$} \\
\hline Container water & 3.171 & $1.212-8.297^{*}$ & & \\
\hline Tap water & 1.00 & Ref & & \\
\hline \multicolumn{5}{|l|}{$\begin{array}{l}\text { Type of cutting } \\
\text { board/instrument }\end{array}$} \\
\hline Wooden & 5.500 & $2.049-14.763^{*}$ & & \\
\hline Plastic & 2.419 & $1.015-5.763^{*}$ & & \\
\hline Stainless steel cutter & 1.00 & Ref & & \\
\hline \multicolumn{5}{|l|}{ Wearing working attire } \\
\hline No & 1.352 & $.417-4.384$ & & \\
\hline Yes & 1.00 & Ref & & \\
\hline
\end{tabular}

Butchers sanitation

$\begin{array}{lll}\text { Poor } & 2.000 & .354-11.296 \\ \text { Fair } & 1.849 & .324-10.548 \\ \text { Good } & 1.00 & \text { Ref }\end{array}$

Use of PPE

$\begin{array}{lll}\text { Poor } & 1.400 & .403-4.862 \\ \text { Fair } & 1.333 & .406-4.373 \\ \text { Good } & 1.00 & \text { Ref }\end{array}$

Ref $=$ Reference variable

${ }^{*} p$-value less than $0.05,{ }^{*} p$-value less than 0.001

a Odds Ratio

b $95 \%$ Confidence interval
Table 4 Occurrence of ESBL- EC within samples collected

\begin{tabular}{|c|c|c|c|c|c|}
\hline \multirow{2}{*}{$\begin{array}{l}\text { Source of } \\
\text { sample }\end{array}$} & \multirow{2}{*}{$\begin{array}{l}\text { No of } \\
\text { samples }\end{array}$} & \multirow{2}{*}{$\begin{array}{l}\text { No. of positive } \\
\text { samples }\end{array}$} & \multirow{2}{*}{$\begin{array}{l}\text { Proportion of } \\
\text { positive (\%) }\end{array}$} & \multicolumn{2}{|c|}{$95 \% \mathrm{Cl}$} \\
\hline & & & & Lower & Upper \\
\hline Breast & 40 & 26 & 65.0 & 50 & 80 \\
\hline Wing & 40 & 21 & 52.5 & 36 & 69 \\
\hline Thigh & 40 & 20 & 50.0 & 34 & 66 \\
\hline Keel & 40 & 19 & 47.5 & 31 & 64 \\
\hline Weighing scale & 40 & 16 & 40.0 & 24 & 56 \\
\hline Cutting board & 40 & 15 & 37.5 & 22 & 53 \\
\hline Total & 240 & 117 & 48.8 & 42 & 55 \\
\hline
\end{tabular}

management strategy. Hence, the results obtained from this study suggest that veterinary/public health intervention needs to focus on promoting good personal hygiene, water and stall sanitation; poster teaching about cross contamination, proper cleaning and disinfecting work surfaces; encouraging the use of stainless steel countertop and plastic cutting board or stainless-steel cutting instrument; and meat handlers need to be educated on the global burden of foodborne diseases as well as its impact upon trade and development. 


\section{Additional file}

Additional file 1: Logistic regression tables for the factors associated with ESBL-EC at retail poultry meat wet-market. (DOCX $17 \mathrm{~kb}$ )

\section{Abbreviations}

ANOVA, analysis of variance; CLSI, clinical and laboratory standards institute; DNA, deoxyribonucleic acid; GDP, gross domestic product; PCR, polymerase chain reaction; SMART, study for monitoring antimicrobial resistance trends; USDA, United States department of agriculture; WHO, world health organization

\section{Acknowledgements}

My special gratitude to Puan Fauziah Nordin of Veterinary Public Health Laboratory, Universiti Putra Malaysia for the kind support towards successful completion of this research.

\section{Funding}

This study was funded by Research University Grant scheme (RUGS), Universiti Putra Malaysia, the research group project no. 01 - 02 - 12 - 1669RU.

\section{Availability of data and material}

The datasets supporting the conclusions of this article are included within the article and its Additional file 1.

\section{Authors' contributions}

ABA designed the study, conducted the research, data analysis and interpretation and drafted the manuscript. SAA conceived the study, provided funding, supervised the study, helped in drafting and approved the final draft. JA and ZZ co-supervised the study, and helped in acquiring the data and deciding upon the study design. All authors have read, contributed and approved the final manuscript.

\section{Competing interests}

The authors declare that they have no competing interests.

\section{Consent for publication}

Not applicable.

\section{Ethics approval and consent to participate}

Exempted by Ethics Committee for Research Involving Human Subjects, Universiti Putra Malaysia, and Institutional Animal Care and Use Committee, Universiti Putra Malaysia.

\section{Author details}

${ }^{1}$ Department of Veterinary Pathology and Microbiology, Faculty of Veterinary Medicine, University Putra Malaysia, 43400 Serdang, Selangor, Malaysia. ${ }^{2}$ Department of Veterinary Clinical Studies, Faculty of Veterinary Medicine, University Putra Malaysia, 43400 Serdang, Selangor, Malaysia. ${ }^{3}$ Department of Pathology and Microbiology, Faculty of Veterinary Medicine, Veterinary Public health laboratory, Universiti Putra Malaysia, 43400 Serdang, Selangor, Malaysia.

Received: 9 September 2015 Accepted: 27 July 2016 Published online: 02 August 2016

\section{References}

1. Rawat D, Nair D. Extended-spectrum $\beta$-lactamases in Gram Negative Bacteria. J Glob Infect Dis. 2010;2(3):263-74.

2. $\mathrm{WHO}$ | Antimicrobial resistance: global report on surveillance. 2014. Available at: http://www.who.int/drugresistance/documents/ surveillancereport/en/

3. Johnson JR, Sannes MR, Croy C, Johnston B, Clabots C, Kuskowski MA, Bender J, Smith KE, Winokur PL, Belongia EA. Antimicrobial drug-resistant Escherichia coli from humans and poultry products, Minnesota and Wisconsin, 2002-2004. Emerg Infect Dis. 2007;13(6):838

4. Vieira AR, Collignon P, Aarestrup FM, McEwen SA, Hendriksen RS, Hald T, Wegener HC. Association between antimicrobial resistance in Escherichia coli isolates from food animals and blood stream isolates from humans in Europe: an ecological study. Foodborne Pathog Dis. 2011;8(12):1295-301.
5. Schwaber MJ, Navon-Venezia S, Kaye KS, Ben-Ami R, Schwartz D, Carmeli Y. Clinical and economic impact of bacteremia with extended-spectrum- $\beta$ lactamase-producing Enterobacteriaceae. Antimicrob Agents Chemother. 2006:50(4):1257-62.

6. De Kraker MEA, Wolkewitz M, Davey PG, Koller W, Berger J, Nagler J, Grundmann $\mathrm{H}$. Burden of antimicrobial resistance in European hospitals: excess mortality and length of hospital stay associated with bloodstream infections due to Escherichia coli resistant to third-generation cephalosporins. J Antimicrob Chemother. 2011;66(2):398-407.

7. Aidara-Kane A, Andremont A, Collignon P. Antimicrobial resistance in the food chain and the AGISAR initiative. J Infect Public Health. 2013;6(3):162-5.

8. Jury KL, Vancov T, Stuetz RM, Khan SJ. Antibiotic resistance dissemination and sewage treatment plants. Curr Res Technol Edu Topics Appl Microbiol and Microbial Biotechnol. 2010;2:509-10.

9. Sekawi Z, Yusof R, Shamsudin MN. Extended-Spectrum $\beta$-LactamasesProducing Escherichia coli from a Tertiary Hospital in Malaysia: Emergence of CTX-M-Type $\beta$-Lactamases Variation. Res J Microbiol. 2008:3(6):489-93.

10. Hashim RB, Husin S, Rahman MM. Detection of $\beta$-lactamase producing bacterial genes and their clinical features. Pak J Biol Sci. 2011;14(1):41.

11. Costa $D$, Vinué $L$, Poeta $P$, Coelho AC, Matos M, Sáenz Y, Torres C. Prevalence of extended-spectrum beta-lactamase-producing Escherichia coli isolates in faecal samples of broilers. Vet Microbiol. 2009;138(3):339-44.

12. Stuart JC, van den Munckhof T, Voets G, Scharringa J, Fluit A, Leverstein-Van Hall M. Comparison of ESBL contamination in organic and conventional retail chicken meat. Int J Food Microbiol. 2012;154(3):212-4.

13. Department of Statistics, Malaysia. Theme: Gross Domestic Product (GDP) by State, 2010. https://www.statistics.gov.my. Accessed 5 Nov 2013.

14. Selangor sawadee, 2015. http://www.2malaysia.com/selangor/info.htm

15. Tourism Selangor: http://www.tourismselangor.my/selangor-in-brief/historyof-selangor/

16. World Poultry Report. Malaysian poultry industry meeting domestic demand. 2014. http://www.worldpoultry.net/Broilers/Markets-Trade/2014/3/ Malaysian-poultry-industry-meeting-domestic-demand-1486503W/.

17. USDA I International Egg and Poultry Review. 2014;17(14) ISSN 1522-5100. http://search.ams.usda.gov/MNDMS/2014/04/PY20140408WIntl PoultryandEgg.pdf

18. Cools I, Uyttendaele M, Cerpentier J, D'haese E, Nelis HJ, Debevere J. Persistence of Campylobacter jejuni on surfaces in a processing environment and on cutting boards. Lett Appl Microbiol. 2005;40(6):418-23.

19. MR U, Maarof F, Robin T, Chai LC, Cheah YK, Mohamad Ghazali F, Radu S. Occurrence and antibiotic resistance of Campylobacter jejuni and Campylobacter coli in retail broiler chicken. Inter Food Res J. 2010;17(2):247-55.

20. Philippe L, Franil T, Patricia B, George GZ, Daryl JH. Evaluation of a chromogenic medium for extended-spectrum beta-lactamase (ESBL)producing Enterobacteriaceae. Canada: University of Manitoba; 2010. ECCMID, Vienna, Austria 10 - 13 April 2010

21. Clinical and Laboratory Standards Institute. Performance standards for antimicrobial disk susceptibility tests. Approved standard, 10th ed. CLSI document M02-A10. Wayne, PA: CLSI; 2010.

22. Hawkey PM. Prevalence and clonality of extended-spectrum $\beta$-lactamases in Asia. Clin Microbiol Infec. 2008:14(s1):159-65.

23. Hawser SP, Bouchillon SK, Hoban DJ, Badal RE, Hsueh PR, Paterson DL. Emergence of high levels of extended-spectrum- $\beta$-lactamase-producing gram-negative bacilli in the Asia-Pacific region: data from the Study for Monitoring Antimicrobial Resistance Trends (SMART) program, 2007. Antimicrob Agents Chemother. 2009;53(8):3280-4.

24. Lahmer RA, Williams AP, Townsend S, Baker S, Jones DL. Antibacterial action of chitosan-arginine against Escherichia coli 0157 in chicken juice. Food Control. 2012;26(1):206-11.

25. Mataragas M, Skandamis PN, Drosinos EH. Risk profiles of pork and poultry meat and risk ratings of various pathogen/product combinations. Int J Food Microbiol. 2008;126(1):1-12

26. Wong $T$, Janet Whyte R, Joyce Cornelius A, Hudson JA. Enumeration of Campylobacter and Salmonella on chicken packs. Br Food J. 2004; 106(9):651-62.

27. Zhu J, Wang Y, Song X, Cui S, Xu H, Yang B, Li F. Prevalence and quantification of Salmonella contamination in raw chicken carcasses at the retail in China. Food Control. 2014:44:198-202.

28. Burgess F, Little CL, Allen G, Williamson K, Mitchell RT. Prevalence of Campylobacter, Salmonella, and Escherichia coli on the external packaging of raw meat. J Food Prot. 2005;68(3):469-75 
29. Mather AE, Reid SWJ, McEwen SA, Ternent HE, Reid-Smith RJ, Boerlin P, Mellor DJ. Factors associated with cross-contamination of hides of Scottish cattle by Escherichia coli 0157. Appl Environ Microbiol. 2008;74(20):6313-9.

30. Harrison WA, Griffith CJ, Tennant D, Peters AC. Incidence of Campylobacter and Salmonella isolated from retail chicken and associated packaging in South Wales. Lett Appl Microbiol. 2001;33(6):450-4.

31. Ismaïl R, Aviat F, Michel V, Le Bayon I, Gay-Perret P, Kutnik M, Fédérighi M. Methods for recovering microorganisms from solid surfaces used in the food industry: a review of the literature. Int J Environ Res Public Health. 2013;10(11):6169-83.

32. Moore G, Blair IS, McDowell DA. Recovery and transfer of Salmonella typhimurium from four different domestic food contact surfaces. J Food Prot. 2007;70(10):2273-80.

33. Tang JYH, Nishibuchi M, Nakaguchi Y, Ghazali FM, Saleha AA, Son R. Transfer of Campylobacter jejuni from raw to cooked chicken via wood and plastic cutting boards. Lett Appl Microbiol. 2011;52(6):581-8.

34. Pérez-Rodríguez F, Castro R, Posada-Izquierdo GD, Valero A, Carrasco E, García-Gimeno RM, Zurera G. Evaluation of hygiene practices and microbiological quality of cooked meat products during slicing and handling at retail. Meat Sci. 2010;86(2):479-85.

35. Kusumaningrum HD, Riboldi G, Hazeleger WC, Beumer RR. Survival of foodborne pathogens on stainless steel surfaces and cross-contamination to foods. Int J Food Microbiol. 2003;85(3):227-36.

\section{Submit your next manuscript to BioMed Central and we will help you at every step:}

- We accept pre-submission inquiries

- Our selector tool helps you to find the most relevant journal

- We provide round the clock customer support

- Convenient online submission

- Thorough peer review

- Inclusion in PubMed and all major indexing services

- Maximum visibility for your research

Submit your manuscript at www.biomedcentral.com/submit 